\title{
2. Deadlocks or dynamics? The state of research on multilevel governance
}

The empirical phenomenon which is covered by the concept of multilevel governance has been studied for a long time. In federal systems, scholars described the rise and various patterns of intergovernmental relations (Poirier et al. 2016; Wright 1988). In unitary states, central-local relations attracted attention (Newton and Goldsmith 1987). Extensive empirical research was stimulated by the rise of territorial politics and reforms of state organizations in Western democracies. Since the 1970 s, many states have gone through processes of regionalization and decentralization (Keating 2013; Hooghe et al. 2010). They adjusted their territorial structures in order to better cope with differentiated demands of regional or local economies and communities. In the 1990s, the concept of multilevel governance started its career in European studies (Marks 1996) and was later adopted in research on international relations (Zürn 2010). The evolution of the EU towards a supranational political union and the increasing number of international organizations, both of which constituted unique political systems beyond the nation state, indicated that politics and policymaking no longer could be contained in territorial boundaries of nation states. While multilevel polities have existed throughout history, regionalization and globalization in modern societies and democracies brought about various new types of governance arrangements within and beyond the state. The fact that the concept of multilevel governance travelled through many research fields in political science and public administration demonstrates the deep impact of these changes in politics and policymaking. The need to take into account the complexity of multilevel politics and policymaking in theories, empirical research and in practice is beyond any dispute.

As mentioned in the introduction, the concept of multilevel governance, which comprises a broad range of different aspects and varieties, is difficult to define. The problem starts with the notion of 'multi'. In studies on the transformation of political orders, it referred to the dispersal of power to the global and European level on the one hand and to regional or local governments on the other (Hooghe and Marks 2001). However, studies on policy coordination between levels often focus on two levels, as effective interactions rarely include actors from a third level on an equal basis. Accordingly, German designations like 'Mehrebenen-Verflechtung' (Benz 1992) or 'Mehrebenenpolitik' (Scharpf 
1994) allude to 'more' than one level, not multiple levels. The label 'multi' nonetheless makes sense not only for the pragmatic reason that it is meanwhile an established term, but also because two-level interactions in policymaking usually are embedded in a wider multilevel context and are influenced by these 'external' conditions. However, it does not indicate a certain number of levels.

In the context of public policy and administration, 'level' refers to territorially defined jurisdictions governed by legitimized authorities. Certainly, jurisdictions within and beyond the state do not always constitute a territory of a government, they can also define an action space of special administrative authorities or intergovernmental cooperation for fulfilling particular functions (Hooghe and Marks 2003), such as, for instance, school districts in the US, waterschappen (water boards) in the Netherlands, or the Eurozone in the EU. Nonetheless, the boundaries of these special-purpose entities regularly coincide with the borders of states or sub-units of states. More precisely, levels or jurisdictions indicate that within these borders there is a government or administration which operates according to specific rules and routines.

A more contested notion is governance, a concept that is 'notoriously slippery' (Pierre and Peters 2000: 7). The numerous definitions concur insofar as they emphasize that governance is about the coordination of many (mostly corporate) actors contributing to a common good. This implies that actors are formally autonomous, endowed with different powers and rights, but functionally interdependent. Furthermore, they can use different strategies and means in processes aiming at coordinated action. The first aspect relates to structures, the second to processes, and the concept of governance encompasses both. It describes a structured constellation of actors interacting in processes with the purpose of achieving a common goal. Structures can be hierarchical, network-like or simply based on interdependence, and they can be more or less institutionalized; actors may come from the public or private sector, and they are relevant as far as they contribute to governance.

It is essential to take into account that multilevel governance constitutes a two-dimensional pattern of politics and policymaking. It links coordination between levels with processes shaping the interests, aims and preferences of those corporate actors who are involved or have a stake in multilevel coordination. As will be outlined in greater detail, the rules and logics of multilevel and intra-level politics differ, and their interference frequently causes conflicts and tensions. This is the reason why policy change is difficult. However, this complexity of structures and processes also entails dynamics of multilevel governance and thus favours change and innovation.

Over the last few decades, extensive empirical research on a broad range of cases of multilevel governance has stimulated theorizing (Bache and Flinders 2015; Benz et al. 2021; Enderlein et al. 2010; Ongaro et al. 2010), with theories developing into different directions. Focusing on multilevel governance in 
the EU, Simona Piattoni (2010: 18-26) distinguishes three approaches. First, the concept describes an opportunity structure for political mobilization of sub-national and non-governmental actors participating in policy networks that span across regional, national and European levels of government. This mobilization changes structures of governance by causing a reallocation of political authority (Marks 1996). Second, in a structuralist turn of the first approach, multilevel governance has been interpreted as a novel form of 'polity-structuring' driven by functional requirements in the provision of public goods, by the pressure of territorially organized communities and by changes in party systems (Hooghe and Marks 2009, 2018). Third, scholars have perceived governance as politics and policymaking in complex institutional configurations and have compared types of multilevel governance and their impact on effectiveness and legitimacy of policies and political decisions (Benz 2000, 2009; Börzel 2010). The first two approaches explain the development, dynamics and varieties of structures of multilevel governance from different angles, the third one directly addresses policy change and thus is particularly relevant for the research question dealt with in this book.

\section{STRUCTURES, DYNAMICS AND DIVERSITY OF MULTILEVEL GOVERNANCE}

The first two approaches focus on changing political structures like European integration or regionalization or internationalization of political authority. Both can be traced back to the groundbreaking works of Liesbet Hooghe and Gary Marks (Hooghe and Marks 2001; Hooghe et al. 2010; Hooghe et al. 2016a; Hooghe et al. 2016b; Marks 1996). They described European integration as a process of a dispersal of powers and intensified interaction across the European, national and regional levels of governance and later confirmed their assumptions by data on regionalization in nation states and the delegation of power to international organizations. Theories elaborated within this framework explain these changes, and indicate the main forces driving the dynamics of multilevel political structures. Hooghe and Marks have not been interested in policy change or policy innovation specifically, although they discovered multilevel governance in studies on the rise of EU regional policy (Hooghe 1995; Marks 1993). Their research sheds light on the dynamics of politics inherent in multilevel structures and explicates how policies can mobilize new actors and thus set off a process of self-enforcing structural change. If we take into account that significant policy change finds expression in changes of institutions, interactions and procedures, this approach to multilevel governance can contribute to our understanding of policymaking under the condition of complexity, although dynamics of politics and structures do not necessarily support policy innovation. 
Not by coincidence, EU structural policy became a crucial case in studies on multilevel governance (Bache 1998, 2008; Benz 2000; Gualini 2004; Piattoni and Polverari 2016). The 1988 reform of the funding scheme delegated power to regions and supported the inclusion of 'social partners' that include associations and businesses with a stake in regional development. This way, policy change mobilized new actors as players in the process of European integration (Marks 1993). It was no longer only national governments and private companies which influenced European policies, now regional and local governments and civil society associations got involved, and governing Europe in this policy field turned into a new kind of governance including the regional and local level. Compared to the traditional model of a federation which still influences debates on European integration, the reality of multilevel governance is less structured by a clear division of power and, rather, evolves in network-like patterns, in less formalized processes that are open to new actors, and in politics that is not only dominated by the governments of the member states endeavouring to extend or maintain their share of the funds, but is also driven by policy specialists and actors interested in enhancing competitiveness of regions or coping with social problems.

Like most case studies on politics spanning across boundaries of jurisdictions, the early studies by Hooghe and Marks used an actor-centred approach to explain the rise of multilevel governance. Later they elaborated a 'postfunctionalist' theory of European integration, the reconfiguration of nation states and the extension of transnational authority (Hooghe and Marks 2009). In line with traditional theories of European integration, they regard the pressure of policy specialists and interest groups as one causal mechanism driving the shift of authority between levels of governance. The functionalist reasoning implies that these actors can justify a redistribution of power as crucial for governing complex tasks. Usually, policy specialists and interest groups include actors who are attached to different levels but agree on the need to share power in a multilevel setting. Since the provision of many public goods requires that governments, public administration and private actors coordinate policies across different jurisdictions, the interaction of policy specialists drives authority migration to the upper level (be it the EU or international organizations) and evolves into intergovernmental relations across levels. Scholars considered this mechanism as the predominant force explaining European integration between the late 1950s and the late 1980s (Hooghe and Marks 2009: 5). Since then, the project of a European Union became a matter of mass politics, which is less about particular interests and distributional bargaining and more about 'identity' of communities and party competition. Communities claim autonomy within multilevel structures and therefore prefer self-rule instead of shared rule (ibid.: 2). Their identity is voiced by regionalist or nationalist movements challenging centralization of power and denation- 
alization or globalization of markets and politics. Political parties convey the rising sense of communities in democratic processes at the national or regional level, in competition with other parties advocating European integration and the transnational cooperation of governments and societies. In consequence, party systems increasingly reveal a new cleavage between the winners and losers of globalization or European integration and between citizens preferring societal diversity and open borders and those arguing for renationalization and closed borders (Hooghe and Marks 2018; Kriesi et al. 2006).

The functionalist and community-based mechanisms drive dynamics of political structures into different directions. Political parties are divided between these alternative options, with the consequence that multilevel governance is increasingly contested and politicized. These tensions set off two particular processes: First, the conflict between the driving forces is usually solved by a division of power between levels of government, with self-rule allowing communities to defend their identities against the functionalist pressure towards integration. Second, depending on the power constellation and the degree of politicization and depoliticization, multilevel governance evolves in a cyclical process fluctuating between trends towards integration and disintegration. Despite this instability, the multilevel system persists as long as both driving forces can be kept in balance. Hence multilevel governance varies between a rise of regional and supranational authority and between the self-rule of governments and sharing of powers among policymakers representing local, regional or national governments or European or international institutions. The dynamics of structures are not determined to evolve in a particular direction, since the relative impact of the different mechanisms varies.

At this point, the theory of multilevel governance elaborated by Hooghe and Marks overlaps with William Riker's theory of federalism as a continuous bargain among governments (Riker 1964). He argued that federations, which Hooghe and Marks would label as type I multilevel governance (Hooghe and Marks 2003), are unstable because office holders at the different levels try to extend or defend their power. By engaging in continuous contests, these actors in political and administrative offices generate self-reinforcing processes that lead either towards centralization of power or towards decentralization, depending on particular circumstances. This view, and Riker's assumption that federal systems are threatened by power centralization rather than disintegration, was clearly influenced by his experience with executive federalism in the US, where presidents and governors dominate the continuous bargaining over power. Against this background, he also argued that an integrated party system can stabilize a balance of power in multilevel governance. In such a system, parties compete for votes at the different levels, they link actors holding power in central, regional or local governments by intra-party discussions, and they increase the probability that these actors move to offices on another 
level. Therefore, office holders attached to integrated parties should not prefer authority migration in one direction, rather they should be interested in keeping a balance of power (Riker 1964: 136; for a more detailed elaboration of this theory see Filippov et al. 2004: 190-96).

There is no doubt that party politics and party systems shape how democratic politics and multilevel governance are linked. Therefore, changes in 'political structuring' of a society, which result from a realignment of cleavages and electoral behaviour, can have significant consequences for bargaining over the allocation of power and resources between levels of government and political competition in multilevel governance. In the US, parties which for a long time were rooted in the states became more nationalized during the second half of the 20th century, a process that had started in European welfare states earlier (Caramani 2004). Here, scholars meanwhile discovered a new cleavage between supporters of European integration and groups feeling the disadvantages of economic competition in the common market. While the former group is represented in mainstream parties, the latter find support in anti-European parties (Kriesi et al. 2006). Despite variations between member states (Hooghe and Marks 2009: 14-18), the overall trend has persisted over the last few decades. Within nation states, regionalist parties have gained ground and politics within traditionally integrated parties now appears to be more territorially differentiated (Detterbeck 2012). These changes of party systems follow from the multilevel character of public policies and the rise of multilevel governance, and party politics constitutes a significant force of power dynamics in multilevel governance.

Tensions between the functional pressure and community demands explain dynamics in the relations between the national, regional and international level, or the domestic-international dimension. In her outline of the multilevel governance's conceptual space, Simona Piattoni added two other dimensions (Piattoni 2010: 26-80). The first, which she labelled centre-periphery, covers relations between constituent entities of a multilevel system. They are characterized as uniform or diverse in terms of culture, equal or unequal in terms of resources, symmetric or asymmetric in terms of powers, and inclusive or exclusive in terms of power-sharing with higher-level governments. The other dimension relates to state-society relations, which vary between state-centred multilevel structures and patterns including private actors and associations in formalized participatory governance arrangements. Again, each dimension implies tensions fostering dynamics, as emphasized by Piattoni (ibid.: 27). As she also makes explicit, changes in the different dimensions call for different explanations, including theories of social change, theories of new regional economy, theories of interest intermediation, or theories of party politics.

As mentioned, this strand of research on multilevel governance and the theoretical approaches that have been elaborated in this context fail to tell us 
much about the causes of policymaking or policy change. They explain the emergence and dynamics of structures of multilevel governance. Yet there is more we can learn from this literature, as is expressed by Piattoni's note summarizing the conceptual history of the term:

[It] denotes a diverse set of arrangements, a panoply of systems of coordination and negotiation among formally independent but functionally interdependent entities that stand in complex relations to one another and that, through coordination and negotiation, keep refining these relations. (Piattoni 2010: 26)

On the one hand, if multilevel governance is highly dynamic this should be reflected in processes of policymaking. They are constrained by the complex institutional configuration of governments and organizations linked in multilevel governance, but these institutions do not establish a static structure. Within this institutional context, volatile patterns of interaction and power relations affect policymaking. On the other hand, the concept of multilevel governance does not cover a particular political system comparable to the concept of the state, but it includes a variety of structures or patterns of interaction. Varieties result from the division or sharing of authority between levels, from the organization of politics at the different levels, and from the horizontal relation among constituent units. Beyond that, endogenous dynamics of multilevel governance contribute to a diversity of patterns of interactions, the inclusion or exclusion of actors or effective power structures.

For this reason, it does not make sense to maintain that multilevel governance either enables or constrains policy change or innovation. Rather, we have to ask which types or patterns of multilevel governance provide conditions that are more or less favourable for policy change or innovation. More so than institutions in general, complex structures linking different institutions provide at the same time opportunities shaping a policy and constraints for policymaking. And by being involved in multilevel politics, policymakers can exploit opportunities and can change or circumvent constraints. Furthermore, as we can conclude from the second strand of theorizing on multilevel governance, the issue is not whether policies change or not, but what type of change can be expected.

\section{POLICYMAKING IN MULTILEVEL GOVERNANCE}

While research on multilevel governance revealed significant advancement of conceptual work, collection of data to describe the diffusion of authority, and theorizing to explain this process, the increasing need and practice of coordination across boundaries of jurisdictions within states, in the EU and in international politics, stimulated studies on policymaking in these new kinds 
of political systems. These studies built on approaches developed in policy science and federalism studies, but against the backdrop of particular conditions of governance beyond the state, they inspired innovative theorizing. In contrast to studies revealing the dynamics of structures of multilevel governance, influential theories on policymaking in multilevel governance suggested that significant policy change cannot be expected. They even seem to explain why multilevel governance comes with a high risk of deadlock. An obvious reason for that outcome seems to be that coordination of policies across levels of government can be obstructed by many actors holding the power to veto a decision. However, this is an overly simplified conclusion which is not supported by empirical research and advanced theorizing. To take a closer look, deadlock may occur, but policy change is possible. The real issue is whether significant change is possible as well. If we focus on this more precise question, we find that most theories of policymaking in multilevel governance do not consider policy innovation as a likely outcome.

In multilevel governance, policymakers are confronted with a fundamental problem, as Robert Putnam indicated in his influential article 'Diplomacy and Domestic Politics' (Putnam 1988). Departing from the predominant view which took states, governments or leaders of governments as drivers of international policymaking, Putnam analysed international politics as a 'two-level game', or, in the terminology used here, a process influenced by politics in two different arenas: international and domestic politics. In consequence, the challenge for policymaking consists of the need to harmonize decisions made in both arenas so that, at the end, decisions contribute to achieving a common purpose. For Putnam, policymaking was not determined by the primacy of international politics or legislation within states, it was a 'game' played by actors involved in politics at both levels. The appropriate strategic action of leaders of governments could solve the problem of a 'double-edged diplomacy' (Evans et al. 1993). Certainly, governments or policymakers in multilevel governance are subject to constraints set by institutions or effective power structures. These constraints vary depending on the type of multilevel governance, but they hardly eliminate any room for manoeuvre for actors. Nonetheless, leaders of governments are involved in divergent rule systems established or emerging in the domestic and international arenas and causing different logics of interaction. The challenge actors face in multilevel governance is to conform to these rules and logics at the same time. This can be quite complicated.

\section{The Joint-Decision Trap}

In 1988, when Putnam's seminal paper was published and stimulated research on international politics, Fritz W. Scharpf's ground-breaking article on 'The 
Joint-Decision Trap' in German federalism and European integration appeared (Scharpf 1988). It dealt with a specific pattern of multilevel governance, which Scharpf discovered in the German federal system and later identified in the European Community. In both cases, policymaking developed incrementally, at best, during the 1970 s and 1980 s, not least because decisions required the consent of governments. Joint-decision making, as Scharpf called this pattern, is based on power-sharing between federal and regional governments or governments of the European member states which compels them to negotiate agreements either according to constitutional or European law or because complex problems cannot be solved and tasks cannot be fulfilled within a single jurisdiction. In Germany, the participation of Länder governments in federal legislation via the Federal Council (Bundesrat), and the participation of the federal government in the improvement of regional economies, agricultural structures and (until 2006) university construction, are typical cases of joint-decision making established by the constitution. In the European Community, legislation in the Council of Ministers could be considered as a similar constellation of multilevel governance, as - until treaty reforms of the $1990 \mathrm{~s}$ - representatives of member state governments had to decide unanimously.

Within these institutional contexts, policies are negotiated among executives speaking and acting for a government. In democratic systems, these actors should pursue the public interest of citizens of the respective state, region or local community. Yet even if this normative claim holds in real policymaking and executives are not guided by their special interests, conflicts intensify due to the multilevel character of policymaking. The public interest is defined in political processes organized at the different levels and within different jurisdictions. In multilevel policymaking, it is turned into preferences of governments. Therefore, interests expressed in multilevel governance are likely to diverge. This is not necessarily due to the rational behaviour of executive actors, but rather because they cannot neglect policies legitimized in 'domestic politics'. In established democracies, elected representatives express the will of peoples, and executives responsible to their government and parliament are expected to act accordingly. Negotiating agreements with other governments is made quite difficult, as negotiators have to comply with these expectations.

Nonetheless, executives involved in negotiations on joint decisions not only have to defend the specific public interest of their constituency or implement mandates of their government, they are also expected to cope with matters beyond their jurisdictions by appropriate accords with representatives of other governments. In consequence, they are confronted with a 'mixed-motive' situation. In joint-decision systems, all participants or at least a significant minority of them can veto a decision that interferes with the interests of their constituency. But likewise, all are expected to come to an agreement in order 
to solve problems. For this reason, diverging institutional incentives prompt strategic action in joint policymaking.

If deadlock occurs, it is neither caused by multilevel governance in general nor by the number of veto players alone. It is the conditions established by politics and governance within jurisdictions, not least the particular pattern of democracy or autocracy, that significantly constrain policymaking. Veto power is inherent in negotiations among executives who aim at an agreement, though negotiations often do not rule out majority decisions. Yet external players like cabinets or parliaments can also have power to prevent decisions, since they regularly have to approve a joint decision resulting from multilevel governance. Whereas the veto power of negotiators in practice is used as bargaining power, and thus affects the substance of package deals or compromises but rarely prevents a joint decision, vetoes of 'external veto players' (Benz 2004: 880 ) tend to cause deadlock in multilevel policymaking, because these actors or decision bodies can only accept or reject a proposed decision. Depending on the linkage between multilevel and domestic politics, external veto power can restrict the negotiation mandates of participants in joint-decision making, modify the bargaining behaviour towards a confrontative style, or cause an agreement by governments or parliaments to fail in domestic ratification. Party competition in democratic states or the internal politicization of redistributive consequences of joint-decision making regularly increases the probability of deadlocks.

The real problem which Fritz W. Scharpf revealed in his empirical research on multilevel governance in German federalism and in the European Community was not deadlock of policymaking but ineffective outcomes of joint-decision making. In line with his analytical approach, which he later elaborated as actor-centred institutionalism (Scharpf 1997), he traced back these effects to policymakers' responses to institutional constraints. In the 'mixed-motive situation', they want to evade a deadlock in intergovernmental negotiations, and therefore settle conflicts by compromises that can be accepted by all governments. Usually such a result is achieved through package deals, by sharing costs and benefits on an equal basis, or by avoiding significant changes of the status quo. Yet by ruling out redistributive consequences of policies, policymakers cannot effectively manage social or economic imbalances among territories or cope with external effects resulting from decentralized policies. Although policymakers are aware of these problems of joint-decision making, a revision of the institutional conditions is unlikely to materialize in this constellation of multilevel governance. Scharpf's notion of the Joint-Decision Trap conceptualized this dilemma. Compelled to come to agreements, policymakers accept ineffective decisions, and at the same time avoid institutional reforms since they are aware that any separation of shared power goes at the expense of one level of government and will be blocked by 
a veto. While policies can be changed incrementally, institutions establishing joint-decision making cannot. In Scharpf's words, a joint-decision system is:

an institutional arrangement whose policy outcomes have an inherent (non-accidental) tendency to be sub-optimal - certainly when compared to the policy potential of unitary governments of similar size and resources. Nevertheless, the arrangement represents a 'local optimum' in the cost-benefit calculations of all participants that might have the power to change it. If that is so, there is no 'gradualist' way in which joint-decision systems might transform themselves into an institutional arrangement of greater policy potential. In order to be effective, institutional change would have to be large-scale, implying the acceptance of short-term losses for many, or all, participants. That is unlikely .... (Scharpf 1988: 270)

In his studies on German federalism, Scharpf pointed out that the detrimental effects of joint-decision making vary between types of policies. The risk of failure is particularly high in redistributive policies (e.g., change of tax rates if the revenues are shared between federal and Länder/local governments, fiscal equalization) or in policies with prevailing redistributive consequences (e.g., federal legislation that implies fiscal burdens for Länder governments responsible for implementing the law). Moreover, negotiations are complicated if intergovernmental agreements on a policy have effects beyond this specific policy field and call for coordination within governments. In this case, the responses of external veto players, be it ministers or civil servants from departments in government not participating in joint-decision making, can obstruct an intergovernmental agreement or its implementation.

Fritz W. Scharpf's article on the Joint-Decision Trap broke new ground in research on multilevel governance and inspired empirical studies on policymaking in the EU multilevel system (Falkner 2011; Héritier 1999; Peters 1997), as well as comparative studies on policymaking in federal systems (Benz 2016a; Blom-Hansen 1999; Painter 1991). This research revealed how actors can escape the trap and how constitutional rules requiring agreements can be modified. As Scharpf always emphasized, his theory covers a specific mode of multilevel governance (Scharpf 2011). In a comparative perspective, power-sharing enforcing cooperation, like joint-decision making in the EU or German federalism, appears as a particular constellation. Except for constitutional amendments, it rarely appears in other federations where powers are separated and governments coordinate their policies in informal negotiations or mutual adjustment. In unitary or regionalized states, executives generally interact in the 'shadow of hierarchy', which allows the central government to solve intergovernmental conflicts and avoid deadlocks by unilateral decisions. In the EU, this constellation appears in market regulation (Börzel 2010), whereas in international politics, governments need to come to agreements, but can also revert to unilaterism by making policies on their own if negotiations 
fail. If powers are separated and governments decide unilaterally, the management of interdependencies occurs through adjustment of their policies, and the same mode of governance applies if governments compete for resources (tax competition; Tiebout 1956) or best practices (yardstick competition; Salmon 2019). In these instances, they respond to policies of other governments in sequences of action and reaction.

Nonetheless, regardless of the institutional structure and the mode of coordination, multilevel governance implies that no government or political organization is fully sovereign or able to make policies autonomously. Governance in the sense of coordinating policies across levels of politics is embedded in a 'polycentric' structure. Regardless of their formal independence, all engaged actors are in some way or another dependent on other actors and outcomes are determined by processes of interaction (Stephan et al. 2019). This mutual dependence not only applies to relations across levels. In the context of democratic states, actors representing governments are accountable to parliaments, but they also have to find the support of political parties or interest groups as well as to consider public opinion. In consequence, the number of actors involved and the logics of interactions make policymaking rather complicated. Therefore, even if multilevel governance does not require joint-decision making, significant policy change seems hardly attainable.

\section{Competition and Level-Shifting}

However, this complicated interplay of multilevel governance and democratic politics varies according to the type of democracy and the mode of coordination in multilevel governance (Benz 2019; Benz and Sonnicksen 2017). Majoritarian democracy in parliamentary systems seems to provide favourable conditions for policy change. In consensus democracies, the room for manoeuvre of governments, which search for agreements in negotiations or intend to adjust their policies to the decisions of other governments, is constrained by their commitments to coalition agreements or accords with private interest groups. So far, comparative research on multilevel governance has not systematically taken into account different patterns of democracy (Benz and Sonnicksen 2021). Due to the growing interest in intergovernmental relations in comparative federalism and varieties of governance in the EU, we know more about the impact of modes of coordination on policymaking. Obviously, cooperation in the shadow of hierarchy or voluntary cooperation with exit options increase the probability of policy change compared to joint-decision making (Painter 1991; Scharpf 2001). In decentralized structures, governments can support experimental policies and competition for best practices, as is explained in theories of 'laboratory federalism' (Kerber and Eckardt 2007; Oates 2005). 
This theory seems to be particularly interesting for research on policy change in multilevel governance. It explains a particular mechanism of coordination based on mutual adjustment that may be conducive to innovation. However, it also illustrates that the effects of mechanisms depend on the conditions under which they operate. The concept of laboratory federalism presumes that policymakers change and improve their policies in response to incentives of yardstick competition. This particular type of competition is determined to improve the overall outcome of decentralized policymaking, an outcome that should be achieved by incentives for governments to learn from others and adopt best practices. In the market, these incentives result from the possibility to increase profits; in democratic politics, yardstick competition motivates policymakers to implement higher-quality standards because this increases their chances to win elections. As Pierre Salmon (2019) has extensively discussed, yardstick competition requires that elected executives in governments can be held accountable by voters and that voters base their decisions in elections on a comparative evaluation of incumbent governments.

There are reasons to assume that citizens compare policies across jurisdictions, and governments have to take this into account. With the rise of a 'monitory democracy' (Keane 2009: 686-98) owing to the growing number of organizations publishing comparative evaluations and data on governance performance, and with regular opinion polls on specific policies conducted or made public by the media, Salmon's focus on government-citizen relations (Salmon 2019: 48-9) might be justified. As Jack A. Walker discovered (Walker 1969: 893-5) and as Andrew Karch confirmed in his study on policy diffusion in the US, national public organizations provide a decisive source for information, communication and comparative evaluation of governments. However, as elected executives and members of parliaments are interested in getting re-elected, an incumbent government might be led to deviate from policy innovations in other jurisdictions (Karch 2010). Even if assessments gained from comparison would influence the voting behaviour of citizens, they affect policymaking of governments only in those policies that are salient for voters. In parliamentary systems, accountability to parliaments constitutes a distinctly more effective mechanism to transform lessons drawn from other jurisdictions and rankings or ratings of policy outcomes into incentives for governments to change policies. If we take elections as the procedure by which citizens hold governments accountable, the general performance of an incumbent government, and not a particular policy, is decisive. However, parliaments hold governments accountable for particular decisions. In presidential systems, executive-legislative relations are comparably less interconnected and it is primarily the pressure of interest groups and lobbyists that influence decisions of governments (Karch 2010: 145-91). 
As Andrew Karch convincingly explained, information about best practices has an impact on the agenda of a government, but innovative policy models are 'customized' (ibid.: 147) in internal processes of legislation and implementation. At this stage, parliaments evaluate policies of the executive in party competition, and so do interest groups as well as lobbyists pursuing their particular aims. Therefore, as in joint-decision making, different mechanisms of politics interfere in the two-dimensional structure of decentralized governance. Comparative evaluations of policies across different jurisdictions may influence democratic processes within governments, but majority and minority parties usually interpret or exploit them in different ways. At least in the US states, domestic interests clearly dominate legislative and administrative processes. These internal forces significantly weaken the incentives for policymakers to change a policy, which in principle are generated through yardstick competition. In the context of party competition an incumbent government is regularly not willing to disclose information about deficits, and in parliamentary systems the majority parties have no interest in enforcing performance evaluation. Executives and majority parties tend to defend their policy against the opposition. Certainly, comparative policy evaluations can be conducted by central government agencies or private organizations. Such externally induced processes of yardstick competition contribute to reduce information asymmetries between executives, parliaments and citizens in accountability relations, and this is their primary function. By uncovering serious deficits in public policies, these processes can initiate policy change, and public discussions instigated by comparative information can stimulate policy learning as a matter of course. Accordingly, yardstick competition constitutes a mode of multilevel governance which is compatible with democracy. Yet if we take into account the context of party and interest politics, this mode of governance seems insufficient to generate policy innovation, although it can contribute to public discourses and improve the quality of democracy (Benz 2012).

As mentioned, multilevel governance has to be conceived as a twodimensional structure and process. Apparently, policy innovation in multilevel governance does not result from competition among governments if this process collides with 'domestic' (intra-governmental) politics. Competition influences a government's policy if it compels adjustments to external pressure. This is the case in 'institutional competition' which concerns the resources of a government, like tax competition in a free market with highly mobile taxpayers. But policy change induced by this mechanism is not always intended and, in the long term at least, can reduce the capacities of governments to respond to economic, social or environmental problems within their own jurisdiction. Adjustments induced by yardstick competition result from the voluntary participation of governments, but this is the reason why the number of domestic veto players and the interference of intra- and intergov- 
ernmental processes often impedes significant policy change. Nonetheless, we should not underestimate the dynamics caused by competition among governments, in particular as it impacts on agendas of politics, contributes to generate knowledge and information, and influences policy ideas.

Another source of policy change or innovation results from the interaction of decentralized and centralized intergovernmental negotiations in a policy field, if they proceed in distinct arenas and processes that are only weakly linked though exchange of information. Such a constellation regularly exists in multilevel governance beyond the state, where institutionalized linkages between levels are less dense compared to multilevel governance within states. Here, governments use the framework of international organizations or international regimes as a venue for meetings. Results of intergovernmental negotiations are summarized in declarations, not in formal agreements, decisions or contracts. This way, executives can gain significant autonomy from their parliaments and parties, as processes at the international and the domestic level are only loosely connected. Autonomy increases when bodies of experts prepare intergovernmental policies. In spite of this formal separation of levels, coordination is possible by way of 'soft governance'.

The 'Open Method of Coordination' (OMC) introduced by the European Commission in 2000 can be considered to be one such type of soft mode of governance, although it was probably meant as a more direct mode of coordination, and in some policies was strengthened through 'blaming and shaming' of national governments. In general, the Commission established a process determined to monitor the performance of member states' policies in selected fields and expected that the results could instigate debates in national parliaments or influence public opinion on necessary reforms. Research on the OMC revealed mixed effects (e.g., Barcevi et al. 2014; Tholoniat 2010; Zeitlin et al. 2005). Apparently, national governments and parliaments had their reservations about the ambitions of the Commission in areas that fall under the jurisdiction of member states. Yet similar policy effects can also result from multilevel processes without a formal procedure of coordination. In a project on financial market regulation after the 2008 crisis, Renate Mayntz and her partners described a case of soft governance in a loosely coupled system of multilevel governance (Mayntz 2015). In case studies on regulatory policy, the research group exposed how national governments uploaded their policies to the European or international level in order to circumvent institutional constraints within their jurisdiction. Via the influence of their experts in the policy field, they transferred their reform agenda to international committees, international organizations or conferences of governments. On the other hand, bodies of international organizations or advisory committees, which lack the power to execute a policy, downloaded their policy to national governments via their contacts to responsible actors in national governments. In turn, these actors 
profited from being supported by international expertise when pursuing their reform policy against resistance within the national government or legislature. This dynamic interplay of policymaking in different bodies or arenas and the sequential shifts between levels explain why regulation could be amended at least partially in a policy field, where rather complicated issues had to be dealt with and where many powerful actors with vested interests or veto rights could prevent change. In such a 'multilevel action system', national, European and international arenas of policymaking framed and shaped decision making at the other levels, and with every shift of a policy from one level to another, its substance changed (see also Kudrna et al. 2014).

\section{Policymaking under the Condition of Complexity}

Similar conclusions have been drawn by scholars who applied complexity theory to federal systems or multilevel governance (Bednar and Page 2016; Schneider 2012). In public policy and governance, complexity finds expression in a concurrence of institutional differentiation of power and functional interdependence of policies. In multilevel governance, the vertical and horizontal differentiation of territorial structures responds to varieties of regional or local conditions, but more often than not the tasks assigned to governments or administrations span the boundaries of their jurisdictions and transcend the scope of political power. Managing interdependence under the condition of diversity and interdependence appears as the basic challenge of complex governance. Scholars have suggested that 'polycentric governance', an interaction of multiple decision centres, constitutes an appropriate pattern to manage complexity. These centres constitute formally independent units. But faced with overlapping jurisdictions, responsible actors holding power in these units should take into account the consequences for other units. They deal with conflicts in processes of competition and cooperation and thus become connected (Thiel et al. 2019). In contrast to institutionalist or actor-centred theories of multilevel governance, complexity theory presumes that the cross-cutting of institutional or territorial and functional boundaries and emergent patterns of interactions creates connectedness, while differentiation and variety of tasks generates behavioural diversity (Bednar and Page 2016). Under these provisions, actors are required to continuously adjust to the dynamics of emergent structures and interactions. Accordingly, multilevel governance is characterized by processes of coordination in which actors mutually learn and change policies in the context of structures that are highly flexible.

Complexity theory mainly explains the stability or instability of systems and aims at finding conditions for the robustness or resilience of governance (Bednar 2009). Scholars applying this approach are mainly interested in principles for designing complex systems that are appropriate to the tasks at 
hand. Accordingly, they assume that policies continuously change in multilevel systems, or they postulate the need for change, but their theory does not explicate the causal mechanisms of policy change. They assume that complex systems emerge and adapt when actors cope with interdependence in differentiated structures. With the emphases of interdependence, connectedness, diversity and adaptability, the theory highlights important conditions for policy change in multilevel governance, although on a high level of conceptual abstraction. By considering complex systems as dynamic, it points out that policy change is necessarily linked to change in structures.

Notably, scholars working on joint-decision making in multilevel governance came to a similar conclusion. In her studies on the EU, Adrienne Héritier, for instance, has discovered that actors tried to find escape routes in order to avoid being trapped in deadlocks of policymaking (Héritier 1999). Furthermore, she described processes of interstitial change of institutions, which occurs in periods before or after institutional reforms, when actors are confronted with the challenges of division and sharing of power and find ways to cope with diverse, often contrasting rules or requirements (Héritier 2007). Accordingly, policymaking in complex multilevel governance results in implicit institutional changes and adjustments.

In his theory of joint-decision making which he elaborated based on case studies on federal-Länder cooperation in Germany, Fritz W. Scharpf already pointed out different ways in which actors who are compelled to cooperate can avoid decision traps (Scharpf 1976). In their empirical studies, Scharpf and his co-authors showed that policymakers usually define issues in a way that reduces the level of conflict, for instance by precluding or compensating redistributive effects of a policy, by avoiding decisions which discriminate among participants, or by postponing controversial issues. In his theory, Scharpf also mentioned ways in which actors can change procedures or actor constellations, for instance by forming coalitions in negotiations, by the sequential treatment of issues, or by bilateral negotiations with pivotal actors. Later research on joint-decision making has demonstrated that changes in the effective structure of policymaking are essential to make multilevel governance work. Accordingly, if powers are shared and coordination has to be achieved in negotiations, a variation of actor constellation should be possible if the policies are made in multiple arenas (political and administrative bodies, coalitions, sub-committees, advisory bodies). Adjusting structures appears as decisive for finding agreements, so that confrontation of executives representing parties or governments can be counterbalanced by bargaining among policy specialists in administration or deliberation among independent experts. Experts and civil servants can 'depoliticize' negotiations, whereas political executives can link different issues to package deals that are acceptable for parties and parliaments (Benz 2016b). Thus, like complexity theory, actor-centred theories of inter- 
governmental policymaking accentuate the relevance of complex structures and adaptation in multilevel governance.

However, neither of these theories explains policy innovation. Regarding policy outcomes, most of them suggest that gradual change is the rule in complex systems and multilevel governance. Complexity theory indicates that significant changes in policies may be driven by changes in structures or actor constellation. In contrast, the theory of joint-decision making suggests that incrementalist policymaking is likely to reinforce structures that constrain policy change.

\section{CONCLUSION}

In general, multilevel governance does not establish favourable conditions for policy innovation. The emergence of structures in complex, polycentric governance and the many constraints established in the intergovernmental and intragovernmental dimension of a multilevel system seem to render significant and intended policy change rather difficult. That we have to understand multilevel governance as a dynamic political structure does not contradict this conclusion. Nonetheless, theories and empirical research on multilevel governance also do not rule out that policy innovation is possible (e.g., Daniell et al. 2014). But we have to presume that it materializes only under specific conditions.

Given the state of research, we cannot draw general conclusions as to whether the increasing complexity of governance within or beyond the nation state increases or decreases the chances for innovative policies. The diversity of patterns of multilevel governance speaks for a differentiated analysis, which will at best lead us to theoretical models covering specific constellations. In consequence, a general theory of multilevel governance consists of partial explanations linked by a conceptual framework. The multifaceted nature of multilevel governance requires us to consider different causal mechanisms which either drive or impede change. The next chapter reviews theories explaining changes of policies, political structures and institutions in order to identify relevant mechanisms. Beyond that, conditions which facilitate or impede significant policy change need to be taken into account, as will be outlined in subsequent chapters. A comprehensive explanation of policy innovation in multilevel governance can only consist of "modular constructs, combining and linking several theoretical "modules" to account for complex and potentially unique empirically observed phenomena or events' (Scharpf 1997: 30). Such a methodological approach proves to be particularly suitable when we are looking at exceptional events. 